\title{
Analysis on dynamic failure behaviors of steel double-layer grids used in a hexagon gymnasium under strong earthquake action
}

\author{
P. C. Wu ${ }^{1, a}, \mathrm{H} . \mathrm{W} . \mathrm{LI}^{1, b_{*}}, \mathrm{~J}$. Liu ${ }^{1, \mathrm{c}}$ \\ ${ }^{1}$ Department of Civil Engineering, Taiyuan University of Technology \\ 79, Yingzexi Street, Taiyuan, 030024, China \\ awpc_ooff@126.com, ' Ihwtut@126.com (corresponding author), \\ ccimeng2005@163.com
}

Keywords: Strong earthquake action, Elasto-plastic dynamic response, Steel double-layer grid, Plastic hinge, Seismic performance

\begin{abstract}
In this paper, the elasto-plastic dynamic analysis on dynamic failure behaviors of a steel double-layer hexagon grid used in a swimming gymnasium with the function of earthquake victim shelter under disaster earthquake is carried out under EL-centro wave with SAP2000, and the appraisal results on their anti-failure performances are presented under strong earthquake action based on the plastic-hinge theory. In the analyses, the geometric and material nonlinear effects are considered simultaneously based on the plastic-hinge theory. The plastic development level of the rod, the deformed shape and the failure type and the ductility are estimated by plastic hinge principle. The results show that the failure model of the structure under the earthquake wave action is elasto-plastic dynamic buckling of the structure. When the structure reached its failure critical limit, the development of the plastic hinges is not sufficient and only $11.1 \%$ of the rods enter into their plastic stage; The ratio of its maximal failure node vertical displacement and its short span is $1 / 171$, which can meet the need for flexible non-structural attachment; Its critical failure peak acceleration of EL earthquake wave when applied in the combination of three directions is 790gal, which is 1.975 times more than the official seismic fortification level of 8 degree (major earthquake, 400gal) and can be served as earthquake victims shelter in the area of 8 degree seismic fortification; Its displacement ductility coefficient is 1.6 ,which shows the structure owns good energy dissipation capacity.
\end{abstract}

\section{Introduction}

Double-layer grid with their structural advantages and good seismic performance are widely used in large span buildings in China. Previous recent disastrous earthquakes show that the large span public buildings were used as earthquake shelters and disaster relief headquarter sites ${ }^{[1]}$. So the large span public buildings newly designed are gradually required to have the function of earthquake shelters. In order to work safely during disastrous earthquakes, the structures of these buildings are required to be designed under strong earthquake action larger than the official seismic major fortification earthquake level. Therefore the appraisal method on their anti-collapse performances under strong earthquake action is needed to be studied. In this paper, the elasto-plastic dynamic analysis on dynamic failure behaviors of a steel double-layer hexagon grid used in a swimming gymnasium with the function of earthquake victims shelter under disaster earthquake is carried out and appraisal results on their anti-failure performances are presented under strong earthquake action based on the plastic-hinge theory ${ }^{[2]}$.

\section{Analysis Model}

A sports practice swimming gymnasium with plane size of $842 \mathrm{~m}^{2}$ and cornice elevation level of $10 \mathrm{~m}$ is shown in Fig.1. Its roof structure is a double-layer hexagon grid with square on square pyramids supported by $400 \mathrm{X} 400 \mathrm{X} 45 \mathrm{X} 70$ joists. Its grid size is a hexagon with the side length of $3 \mathrm{~m}$, its grid height is $1.5 \mathrm{~m}$. The gymnasium structure is designed firstly according to the current 
national standards with official seismic fortification level of 8 degree (major earthquake, 400gal) and site classification of type III, design reference period of 50 years, design characteristic period of ground motion of $0.45 \mathrm{~s}$. Its peak ground acceleration for the small and the major earthquake is respectively $70 \mathrm{gal}$ and $400 \mathrm{gal}^{[3]}$. The damp is taken as Rayleigh with the damping ratio $0 \mathrm{f} 0.02$ or 0.05 for elasticity or elasto-plasticity. The material adopts bilinear elastic-plastic material model with the density $7850 \mathrm{Kg} / \mathrm{m} 3$, elasticity modulus $2.06 \mathrm{Gpa}$, tangent modulus $6.18 \mathrm{GPa}$, the Poisson ratio 0.3 , and the yield strength $235 \mathrm{MPa}$. The top chord cross section sizes are $\varphi 89 \mathrm{X} 4, \varphi 76 \mathrm{X} 6$ and $\varphi 60 \times 3.5$, the lower chord cross section sizes are $\varphi 89 \times 4, \varphi 76 \times 4$ and $\varphi 60 \times 3.5$, the web member cross section sizes are $\varphi 89 \times 4, \varphi 76 \times 4, \varphi 60 \times 3.5$ and the cross section size used in the joists is 400X400X45X70. The nonlinear analysis on the spatial truss under EL-Centro wave is carried out with plastic hinge method by SAP2000. The generalized force-displacement relation for the plastic hinge defined in the members of the structure is defined according to FEMA356 ${ }^{[4]}$.
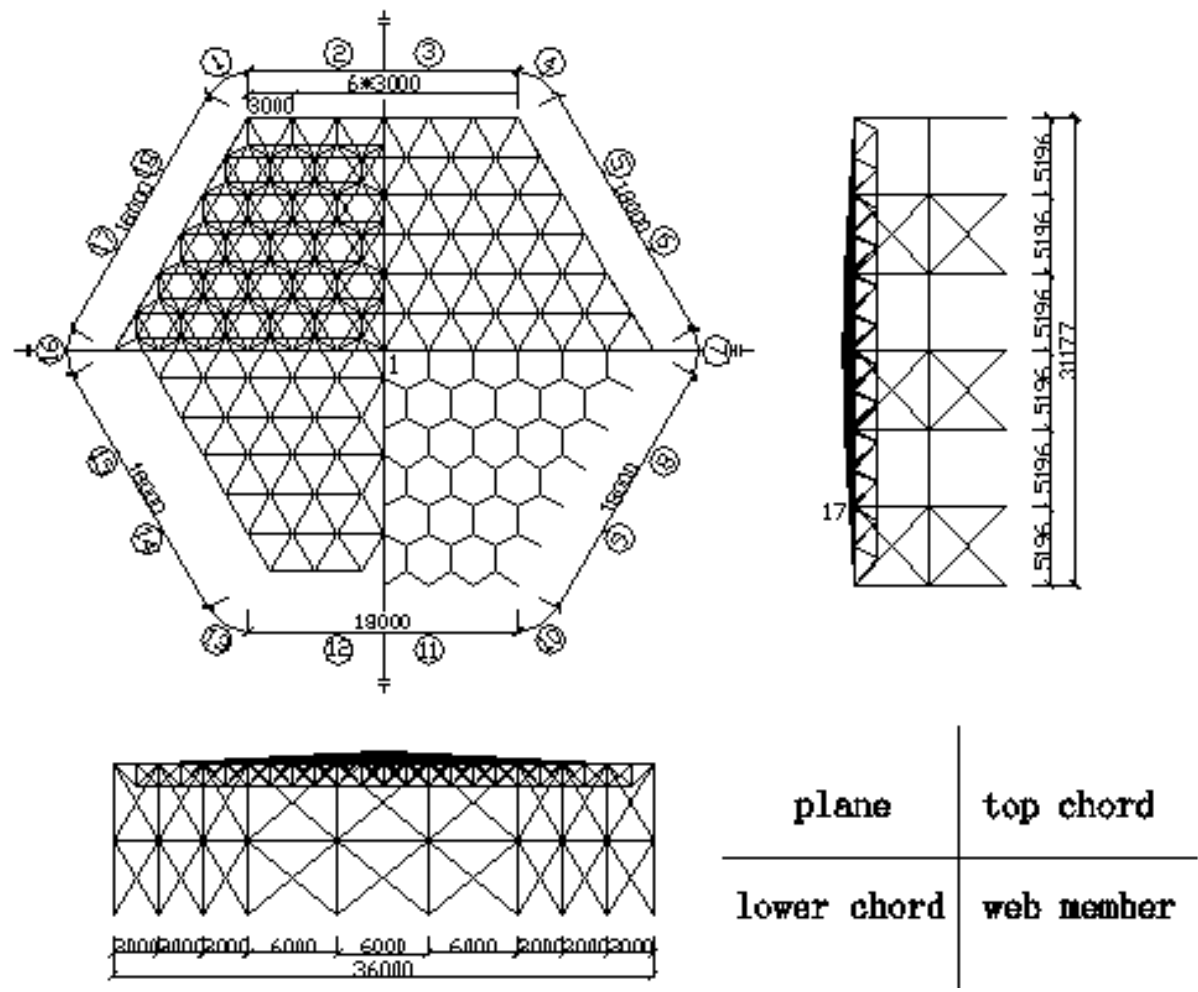

Fig. 1 Structure layout

(The node number shown in this figure is feature node)

\section{Results and Analysis}

Nonlinear time history calculations on the model are carried out by SAP2000 with El-Centro wave applied in the combine direction of $\mathrm{X}+0.85 \mathrm{Y}+0.65 \mathrm{Z}$. The initial condition for each time-history calculation is the deformed state of the structure under the whole dead load and the half snow load. Many calculations with different peak value of the input earthquake wave applied to the structure designed according to the official Seismic fortification level are carried out to find two limit conditions for the structure. The first is the elastic limitation; the second is elastic-plastic critical failure limitation. The plastic hinge distribution is shown in Fig.2. The node 1 and node 17 with maximum displacement in the structure is chosen as the characteristic node in the description. The failure mode at 791gal, the relationship curve between the maximum node displacement and peak ground acceleration (shorted as PGA), the time history displacement response of the characteristic node are respectively shown in Fig.3, Fig.4 and Fig.5. Its displacement ductility coefficient, the number and the distribution of the plastic hinge are provided respectively in Tab.1 and Tab.2. 


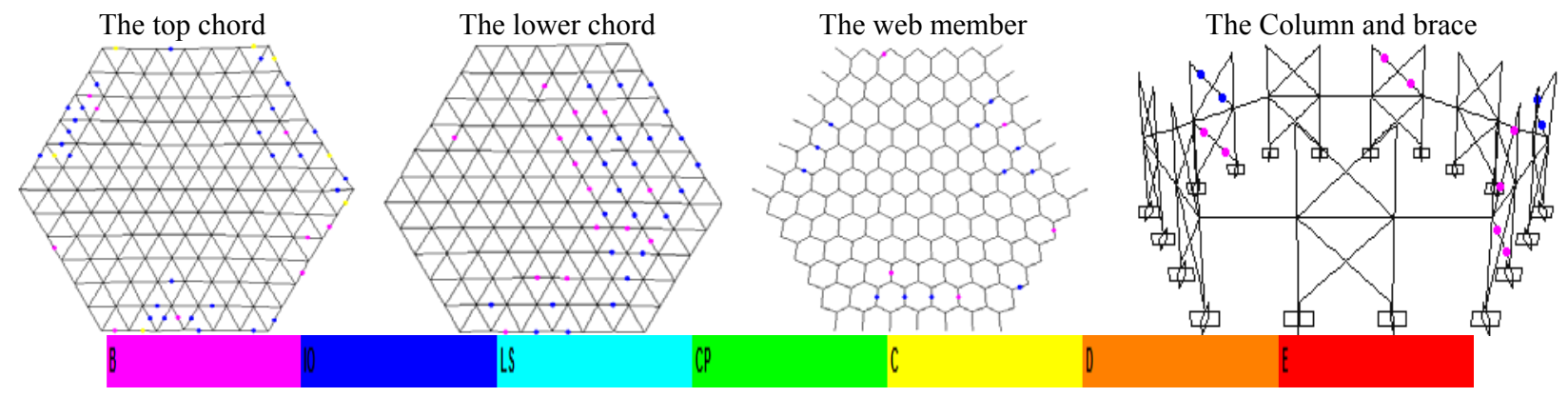

Fig.2 The structural plastic hinge distribution at 790gal
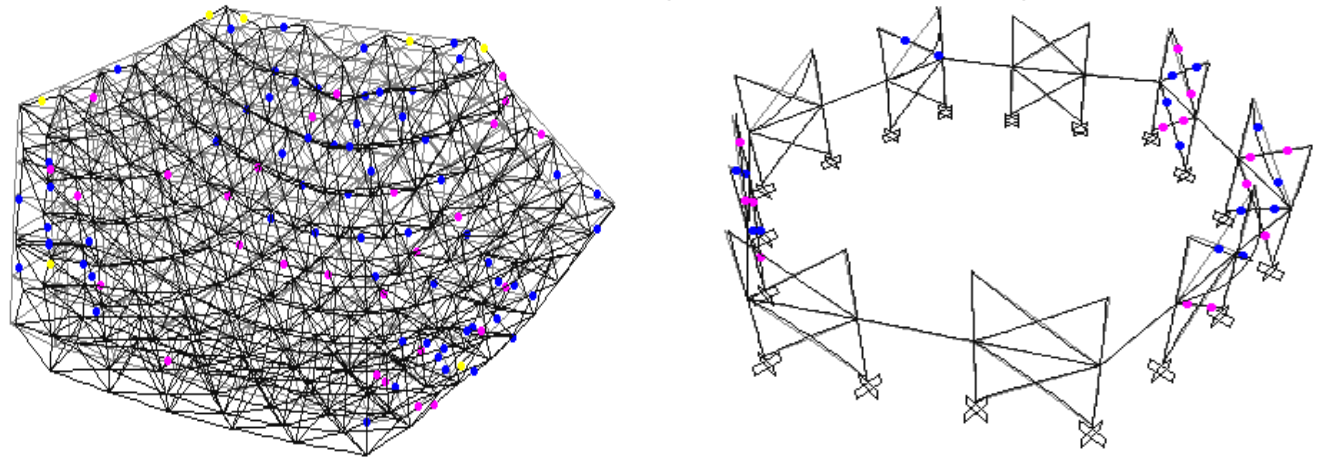

Fig. 3 The failure mode at 791gal

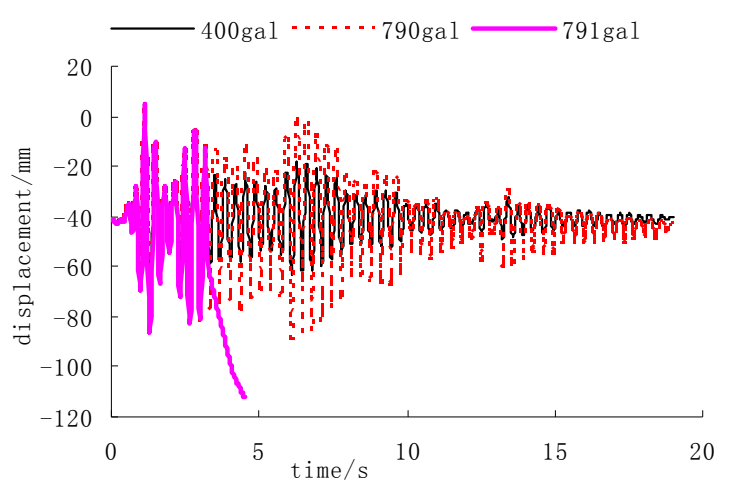

Fig. 4 Disp. time history curves of Node 1

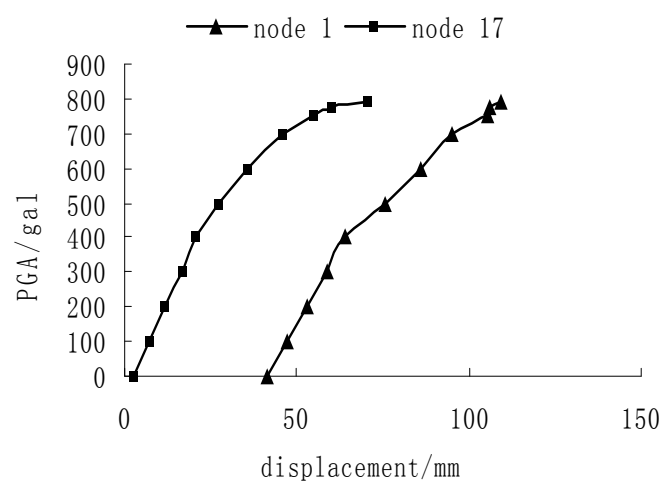

Fig. 5 The peak value of the node 1 and 17 displacement -PGA curve

Tab.1 Critical PGA for two limitations of structure and displacement ductility coefficients

\begin{tabular}{|c|c|c|cc|}
\hline Critical PGA (gal) & $\begin{array}{c}\text { Node } \\
\text { number }\end{array}$ & $\begin{array}{c}\text { Structure vertical } \\
\text { displacement U3(mm) }\end{array}$ & U3/L & $\begin{array}{c}\text { yield } \\
\text { Displacement } \\
\text { ratio }\end{array}$ \\
\hline 0 & 1 & 41.17 & $1 / 437$ & - \\
\hline 400 & 1 & 64.16 & $1 / 280$ & 1 \\
\hline
\end{tabular}




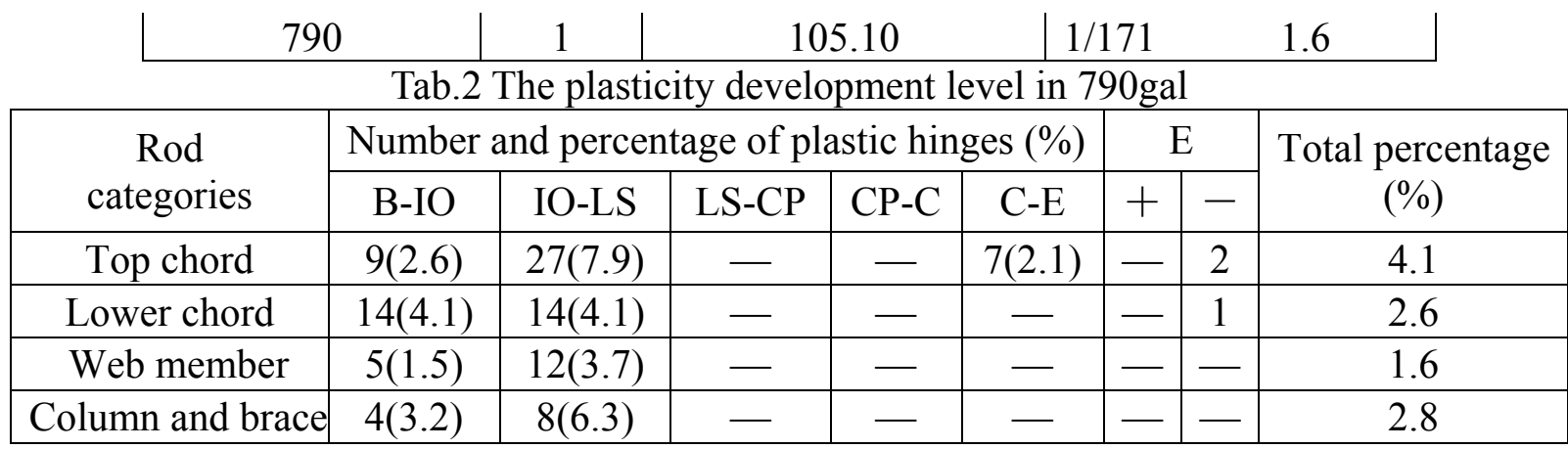

Note: "—" indicates that no plastic hinge; The value in the brackets means the percentage of the rods with plastic hinge in all rods.

According to Tab.1 2 and Fig.2 4, the results can be concluded as follows:

The elastic limitation PGA for three direction input is 400gal. It is much larger than the PGA of the official SEL for small earthquake (70gal).

According to the B-R criterion ${ }^{[5][6]}$, the failure model of the structure under the EL earthquake wave action is the elasto-plastic dynamic buckling, and the critical PGA is 790gal. It is much larger than the PGA of the official SEL for major earthquake (400gal).

The displacement ductility coefficient is 1.6 for the structure, and the ratio of its bars with plastic hinge appearing for ultimate critical state is $11.1 \%$, the development of the plastic hinges is not sufficient. All members in the E stage are in compression state, which gradually develop to whole grids elasto-plastic dynamic buckling. All results about show the structure have some energy-dissipation capacity before elasto-plastic dynamic buckling under earthquake.

\section{Summary}

The failure model of the structure under the EL earthquake wave action is the elasto-plastic dynamic local buckling caused by its rods' compression failure; When the structure reached its failure critical limit, the development of the plastic hinges is not sufficient and only $11.1 \%$ of the rods enter into their plastic stage; The ratio of its maximal failure node vertical displacement and its short span is $1 / 171$, which can meet the need for flexible non-structural attachment; Its critical failure peak acceleration of EL earthquake wave when applied in the combination of three directions is $790 \mathrm{gal}$, which is 1.975 times more than the official seismic fortification level of 8 degree (major earthquake, 400gal) and can be served as earthquake victims shelter in the area of 8 degree seismic fortification; Its displacement ductility coefficient is 1.6 for the structure, which shows the structure owns some energy dissipation capacity.

\section{Acknowledgements}

This project is financially supported by National Natural Science Foundation of China (50878137); Key Project Foundation of Shanxi Province (20080321086) and Shanxi Province Foundation for Scholar Returned From Abroad (2009-26).

\section{References}

[1] H.W. Li, H.S. Zhao, Y.J. Zhao: Study on Planning for the Indoor-earthquake-shelter in City and Town. (Advanced Science Letters), USA, 2011,Vol. 4, pp.2654-2665.

[2] Civil King Software Technology Co., Ltd. China institute of Building Standard Design \& Research. Usage Guide to Structure Analysis Program SAP2000 Chinese Edition [CP] (China communications press, China, 2006),p.460.

[3] GB50011-2010(2010 edition) Code for seismic design of buildings[S]. (China architecture \& building press, Beijing, 2010).

[4] FEM 356 The Seismic Rehabilitation of Buildings[S]. Federal Emergency Management Agency, 2000. 
[5] S.S. Zhao and C. Xin: Dynamic stability of grid structure[M] (Beijing, Science Press, 1999).

[6] H.W. Li, J.X. Li, F. Zhi, F. Ma and D.Q. Qin: Proceedings of the 6th International Conference on Computation of Shell and Spatial Structures IASS-IACM (Cornell University, Ithaca, NY, USA, May 28-31, 2008). 